\title{
Thermomechanical behavior of an electrically conductive cylindrical implant under the action of external unstable electromagnetic fields
}

\author{
Musii R. S., Melnyk N. B., Drohomyretska Kh. T., Zakaulova J. V. \\ Lviv Polytechnic National University, \\ 12 S. Bandera Str., 79013, Lviv, Ukraine
}

(Received 13 December 2020; Revised 19 February 2021; Accepted 25 February 2021)

\begin{abstract}
A physical and mathematical model for determining the thermostressed state of an electrically conductive cylindrical implant under the action of external unstable electromagnetic fields, in particular the impulse with amplitude modulation, is proposed. This model allows predicting the maximum allowable values (according to physiological norms) of temperature and stress intensities in the considered implant depending on the parameters of external unstable electromagnetic fields and the time of their action.
\end{abstract}

Keywords: electrically conductive implant, cylinder, unstable electromagnetic field, temperature, stress intensities, physiological criteria.

2010 MSC: 74A10, 74B10, 74H10

DOI: $10.23939 / \mathrm{mmc} 2021.02 .184$

\section{Introduction}

In the practice of surgical dentistry and orthopedics of the upper and lower extremities, implants of different configurations are often used to connect fractures and to create a rod-base to which is attached either a single tooth or a whole denture-bridge for two implants, as well as to connect fractures of the extremities [1]. The geometric shape of such implants can be modeled with a solid cylinder. Implants made of electrically conductive non-ferromagnetic materials or their alloys, which are stainless steels with appropriate alloying impurities of rare earth elements: chromium, titanium, nickel, vanadium, tungsten [2-5], are mostly used. In the course of life, a patient with an existing implant (in the jaw or extremities) may be exposed to external unstable electromagnetic fields (EMF). Such EMFs are created by appropriate medical devices (UWF devices, computer tomographs, etc.) or household or industrial devices [6]. Their effect on the cylindrical implant in question is manifested by two physical factors - Joule heat and volumetric ponderomotive forces [7]. These physical factors create in the implant a non-stationary temperature field and mechanical stresses and stress intensities. In order to ensure comfortable physiological conditions of the patient's life, it is necessary to be able to predict the thermomechanical behavior of the implant available to him.

In this paper, a physical and mathematical model for determining the thermally stressed state of an electrically conductive cylindrical implant under the action of external unstable EMFs of characteristic types is proposed [8]. This model allows to predict the determination of the maximum allowable values of temperature and stress intensity according to physiological norms depending on the parameters of external unstable EMF [9] and the time of their action.

\section{Basic relations of the physical and mathematical models of the implant}

To determine the thermally stressed state of the cylindrical implant in question, we will proceed from the consistently related Maxwell relations and the dynamic thermoelasticity problem. The rod implant is modeled with a continuous electrically conductive cylinder of radius $R$ and length $L$. Taking into account that $R / L \ll 1$, we will consider the implant in the approach of a long cylinder. The side surface of the cylindrical implant, which is in direct contact with the bone, is considered insulated and free from external surface load. 
A cylindrical implant is considered in a cylindrical coordinate system $(r, \varphi, z)$, the axis $O z$ of which coincides with the axis of the cylinder. The cylinder material is homogeneous, isotropic and nonferromagnetic. Physical and mechanical characteristics of the implant material are constant in the considered temperature change range.

The influence of external unstable EMF on the implant is manifested by the appearance of Joule heat sources $Q$ and volume-distributed non-stationary ponderomotive forces $\boldsymbol{F}$. These two physical factors create additional non-stationary temperature $T$ and mechanical stresses described by the components $\sigma_{r r}, \sigma_{\varphi \varphi}$ and $\sigma_{z z}$ of the dynamic stress tensor $\hat{\sigma}$ in the implant. The components $\sigma_{j j}(j=r, \varphi, z)$ of the tensor $\hat{\sigma}$ are considered as the sum of two components $\sigma_{j j}=\sigma_{j j}^{Q}+\sigma_{j j}^{F}$. The components $\sigma_{j j}^{Q}$ are due to the Joule heat $Q$, and the components $\sigma_{j j}^{F}$ are due to the ponderomotive forces $\boldsymbol{F}$. According to the obtained total stresses $\sigma_{j j}$, we determine the stress intensities $\sigma_{i}$ according to the formula [10]

$$
\sigma_{i}=\sqrt{\left(3 I_{2}-I_{1}^{2}\right) / 2}
$$

Here $(j=1,2)$ is the $j$-th invariant of the stress tensor $\hat{\sigma}$.

The physiologically comfortable condition of the patient with the implant under the action of external unstable EMF will be maintained under certain conditions. Such conditions correspond to the fact that the maximum values of temperature $T$ and intensities of mechanical stresses $\sigma_{i}$ on the surfaces of the implant which are in contact with the bone will not exceed the limit physiologically acceptable values $T_{*}$ and $\sigma_{i *}$. These values correspond to the experimentally established values of the limits of temperature and mechanical pain thresholds. The formulated criteria of physiologically admissible values of temperature and intensity of stresses are mathematically written down by expressions

$$
T_{\max } \leqslant T_{*} ; \quad \sigma_{i \max } \leqslant \sigma_{i *}
$$

Values $T_{\max }$ and $\sigma_{i \max }$ are calculated on the side surface $r=R$ of the cylinder.

Based on the formulated physical and mathematical model, the calculation model for determining the temperature $T$, stresses $\sigma_{j j}$ and stress intensities $\sigma_{i}$ consists of three stages. In the first stage, based on Maxwell's relations from the equation

$$
\frac{\partial^{2} H_{z}}{\partial r^{2}}+\frac{1}{r} \frac{\partial H_{z}}{\partial r}-\sigma \mu \frac{\partial H_{z}}{\partial t}=0
$$

under the boundary condition on the side surface of the cylinder

$$
H_{z}(R, t)=H_{z 0}(t)
$$

conditions of axisymmetry on the axis of the cylinder $r=0$

$$
\frac{\partial H_{z}(0, t)}{\partial r}=0
$$

and zero initial condition

$$
H_{z}(r, 0)=0
$$

we determine the axial component $H_{z}(r, t)$ of the magnetic field vector $\boldsymbol{H}=\left\{0 ; 0 ; H_{z}(r, t)\right\}$. Here $H_{z 0}(t)$ is experimentally established law of change in time $t$ of an axial component $H_{z}$ on a surface $r=R$ of the cylinder; $\sigma$ is the electrical conductivity coefficient, $\mu$ is the magnetic permeability of the cylinder material.

In the second stage, taking into account the known Joule heat $Q(r, t)$ from the heat conduction equation

$$
\frac{\partial^{2} T}{\partial r^{2}}+\frac{1}{r} \frac{\partial T}{\partial r}-\frac{1}{\kappa} \frac{\partial T}{\partial t}=-\frac{1}{\lambda} Q
$$


subject to heat insulation of the surface $r=R$

$$
\frac{\partial T(R, t)}{\partial r}=0
$$

conditions of axisymmetry of temperature on the axis of the cylinder $r=0$

$$
\frac{\partial T(0, t)}{\partial r}=0
$$

and zero initial condition

$$
T(r, 0)=0
$$

we write the temperature expression $T(r, t)$. Here, $\kappa, \lambda$ are the coefficients of thermal diffusivity and heat conductivity of the implant material.

In the third stage, according to the obtained temperature $T(r, t)$ and the component $F_{r}(r, t)$ of the ponderomotive force, we determine the radial component $u_{r}(r, t)$ of the displacement vector $\boldsymbol{u}=$ $\left\{u_{r} ; 0 ; 0\right\}$ from the equation

$$
\frac{\partial^{2} u_{r}}{\partial r^{2}}+\frac{1}{r} \frac{\partial u_{r}}{\partial r}-\frac{u_{r}}{r^{2}}-\frac{1}{c_{1}^{2}} \frac{\partial^{2} u_{r}}{\partial t^{2}}=\alpha \frac{1+\nu}{1-\nu} \frac{\partial T}{\partial r}-\frac{(1+\nu)(1-2 \nu)}{E(1-\nu)} F_{r}
$$

under boundary conditions

$$
(1-\nu) \frac{\partial u_{r}}{\partial r}+\nu \frac{u_{r}}{r}-\alpha(1+\nu) T=0
$$

on the side surface $r=R$ of the implant, the axisymmetry conditions

$$
\frac{\partial u_{r}(0, t)}{\partial r}=0
$$

on the axis of the cylinder and the zero initial condition

$$
u_{r}(r, 0)=0
$$

Here $c_{1}=(E(1-\nu)) /(\rho(1+\nu)(1-2 \nu))^{-1 / 2}$ is the speed of the elastic wave of expansion of the cylindrical implant during its isothermal deformation; $\alpha, \nu$ coefficients of linear heat expansion and Poisson, $E$ is the Young 's modulus, $\rho$ is the density of implant material.

According to the found total radial displacements $u_{r}(r, t)=u_{r}^{Q}(r, t)+u_{r}^{F}(r, t)$ from the relations

$$
\begin{gathered}
\sigma_{r r}=\frac{E}{(1+\nu)(1-2 \nu)}\left[(1-\nu) \frac{\partial u_{r}}{\partial r}+\nu \frac{u_{r}}{r}-\alpha(1+\nu) T\right], \\
\sigma_{\varphi \varphi}=\frac{E}{(1+\nu)(1-2 \nu)}\left[(1-\nu) \frac{u_{r}}{r}+\nu \frac{\partial u_{r}}{\partial r}-\alpha(1+\nu) T\right], \\
\sigma_{z z}=\nu_{n}\left(\sigma_{r r}+\sigma_{\varphi \varphi}\right)-\alpha E T
\end{gathered}
$$

we determine the total stresses $\sigma_{j j}(j=r, \varphi, z)$ and the corresponding stress intensities $\sigma_{i}$ by formula (1).

Based on the obtained expressions of temperature $T$ and stress intensity $\sigma_{i}$ and their values on the cylinder surface $r=R$, we analyze according to the accepted criteria (2) the maximum allowable values of the parameters of external unstable EMF, which provide physiologically comfortable conditions for the patient. 


\section{Constructions of solutions of initial-boundary value problems under the action of homogeneous nonstationary EMF}

To construct the solutions of the initial-boundary value problems of electrodynamics (3)-(6), heat conductivity (7)-(10) and thermoelasticity (11)-(14) formulated above, we apply the approximation of all key functions $\Phi(r, t)=\left\{H_{z}(r, t), T(r, t), u_{r}(r, t)\right\}$ in radial variable $r$ by cubic polynomials [11]:

$$
\Phi(r, t)=\sum_{i=0}^{3} a_{i}^{\Phi}(t) r^{i} .
$$

The coefficients $a_{i}^{\Phi}$ of the approximation polynomials (18) are given as a linear combination

$$
a_{i}^{\Phi}(t)=a_{i 1}^{\Phi} \Phi_{1}(t)+a_{i 2}^{\Phi} \Phi_{2}(t)+a_{i 3}^{\Phi} \Phi^{+}(t)
$$

of the limit value $\Phi^{+}(t)$ of the desired functions on the surface $r=R$ of the implant and the integral (with respect to the radial variable) characteristics

$$
\Phi_{s}(t)=\frac{s+1}{R^{s+1}} \int_{0}^{R} \Phi(r, t) r^{s} d r, \quad s=1,2
$$

of the key functions $\Phi(r, t)$.

The equation for integral characteristics $\Phi_{s}(t)$ is obtained by integrating the original equations (3), (7), (11) according to formula (20) and using expressions (18), (19) in analytical transformations.

As a result, we obtain the following representations of the key functions in a continuous cylinder in terms of their integral characteristics and surface values (as they differ from zero):

- for the axial component $H_{z}(r, t)$ of the vector $\boldsymbol{H}$

$$
\begin{aligned}
H_{z}(r, t)= & H_{z 1}(t)\left(20-100 r_{*}^{2}+80\left(r_{*}\right)^{3}\right)+H_{z 2}(t)\left(-30+180\left(r_{*}\right)^{2}-150 r_{*}^{3}\right) \\
& +H_{z}^{+}(t)\left(1-10 r_{*}^{2}+10 r_{*}^{3}\right) ;
\end{aligned}
$$

- for temperature $T(r, t)$ under the condition of heat insulation of the cylinder surface $r=R$

$$
T(r, t)=T_{1}(t)\left(-19+90 r_{*}^{2}-60 r_{*}^{3}\right)+T_{2}(t)\left(14-60 r_{*}^{2}+40 r_{*}^{3}\right) ;
$$

- for the radial component $u_{r}(r, t)$ of the displacement vector $u$

$$
\begin{aligned}
u_{r}(r, t)= & u_{r 1}(t)\left(20-100 r_{*}^{2}+80 r_{*}^{3}\right)+u_{r 2}(t)\left(-30+180 r_{*}^{2}-150 r_{*}^{3}\right) \\
& +\alpha_{1} r_{*} T(r, t)+\alpha_{2} r_{*} F_{r}(r, t) .
\end{aligned}
$$

Here $r_{*}=r / R$ is the dimensionless radial coordinate, $\alpha_{1} r_{*}, \alpha_{2} r_{*}$ are the corresponding cubic polynomials with respect to the variable $r_{*}$. Based on the obtained expressions of the axial component (21)-(23), we write the solution of the considered problem under the action of a homogeneous nonstationary EMF.

\section{Computer analysis of thermomechanical behavior of the implant under the action of unstable EMF}

The action of an external unstable EMF is given by the value of the axial component $H_{z}$ of the vector $\boldsymbol{H}$ on the surface $r=R$ of the cylinder as a function [8]

$$
H_{z}^{+}(t)=k H_{0}\left(e^{-b_{1} t}-e^{-\beta_{2} t}\right) \cos \omega t .
$$

Mathematical Modeling and Computing, Vol. 8, No. 2, pp. 184-191 (2021) 
Here $k$ is the normalization factor; $H_{0}$ is the amplitude of electromagnetic oscillations with circular frequency $\omega ; \beta_{1}$ and $\beta_{2}$ are parameters characterizing the times $t_{\text {incr }}$ of increase of the amplitude of electromagnetic oscillations of the frequency $\omega$ from zero to its maximum value $H_{0}$ and $t_{d e c r}$ is the decrease of this amplitude from the value $H_{0}$ to zero. Time of action of unstable EMF is $t_{i}=t_{\text {incr }}+t_{\text {decr }}$. Unsteady EMF, which is mathematically described by expression (24), has the character of impulsed EMF with amplitude modulation [8,9,12-17].

Substituting the expression (24) of the function $H_{z}^{+}(t)$ in the relation (3)-(23), we obtain the expressions of Joule heat $Q$, radial component $F_{r}$ of the vector of ponderomotive force $\boldsymbol{F}$ and temperature $T$, radial displacements $u_{r}$ and corresponding stresses $\sigma_{j j}(j=r, \varphi, z)$ under the action of unstable EMF.

For numerical analysis, stainless steel (with doped impurities of chromium, nickel and titanium) was chosen for the implant material. Electrophysical and thermophysical characteristics of steel were selected according to the data given in the literature $[8,11]$. For calculations, it was assumed that the radius of the cylinder is $R=1 \mathrm{~mm}$, and the duration of the electromagnetic action are $t_{i}=10 \mathrm{~s}, 100 \mathrm{~s}$, $300 \mathrm{~s}, 600 \mathrm{~s}$. Accordingly, the value $H_{0}$ is chosen equal to $H_{0}=1 \mathrm{~A} / \mathrm{m}, 10 \mathrm{~A} / \mathrm{m}, 10^{2} \mathrm{~A} / \mathrm{m}, 10^{3} \mathrm{~A} / \mathrm{m}$. The circular frequency is equal to the value $\omega=6.3 \cdot 10^{5} \mathrm{rad} / \mathrm{s}$ belonging to the radio frequency range. This value is outside the resonant EMF frequencies of the cylindrical implant under consideration.

The results of calculations of changes in time $t$ of Joule heat $Q$, radial component $F_{r}$ of ponderomotive force, temperature $T$ and stress intensities $\sigma_{i}$ on surfaces $r=R ; 0.5 R ; 0.25 R$ (lines 1-3) for the duration $t_{i}=10 \mathrm{~s}$ of action of unstable EMF are shown in Figs. 1-4.

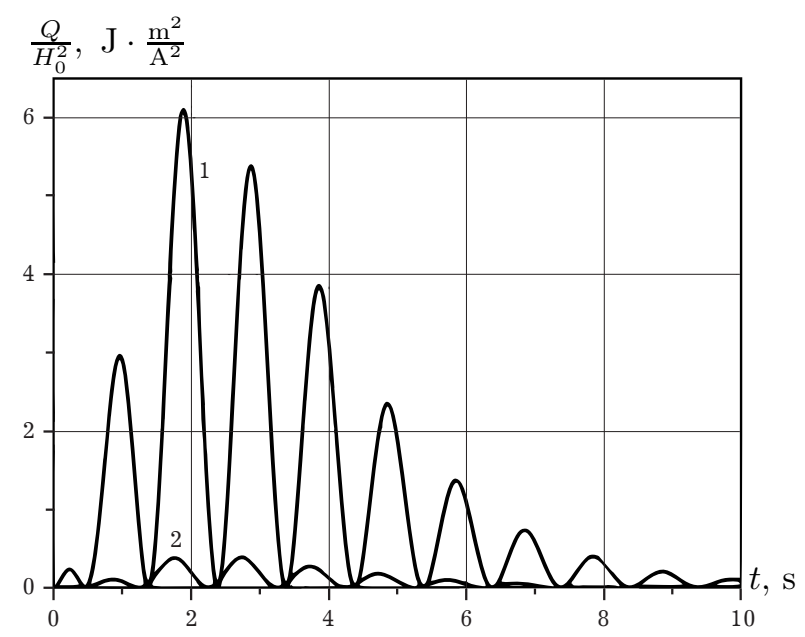

Fig. 1. Change in time of Joule heat generation in a solid cylinder.

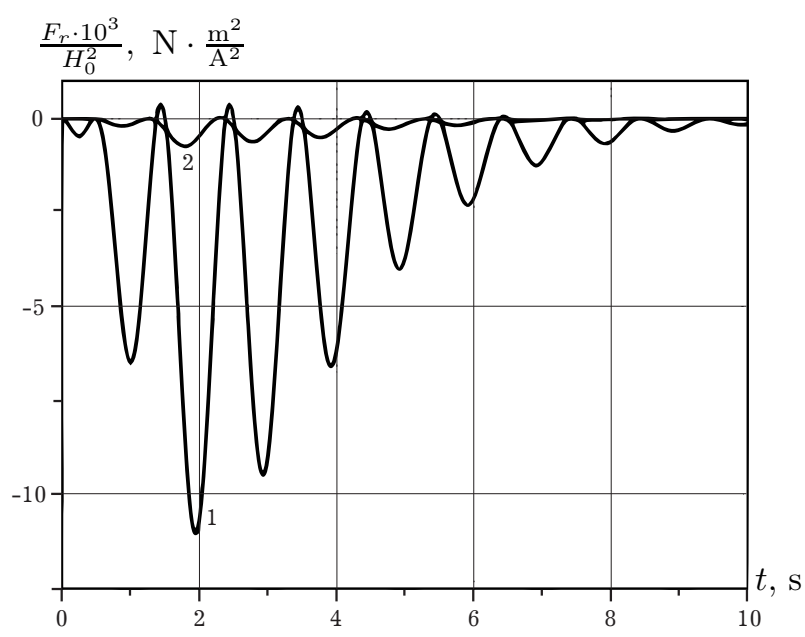

Fig. 2. Change in time of the ponderomotive force in a continuous cylinder.

The change in time of Joule heat $Q$ for each specified value of the radial coordinate has the character of a sequence of heat impulses during the considered electromagnetic action. In each of these heat impulses, the maximum value of the amount of heat released in the cylinder corresponds to the nature of the change in time of function (24), which describes the unstable nature of the external EMF. There is a pronounced heating of the cylinder, which is close to the surface.

The change in time of the radial component of the ponderomotive force $F_{r}$ during the considered electromagnetic action has the character of a sequence of force impulses. The maximum values of the ponderomotive force in the cylinder similarly correspond to the nature of the change in time of the function (24).

The nature of the change in time of the temperature corresponds to its increase in accordance with the nature of the change in time of the heat impulses caused by the Joule heat. 


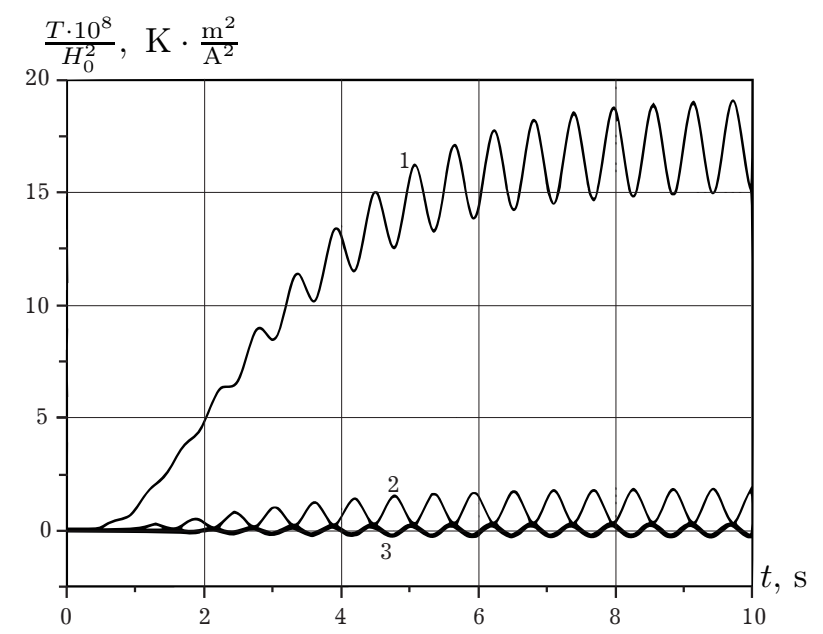

Fig. 3. Change in time of the total temperature in a solid cylinder.

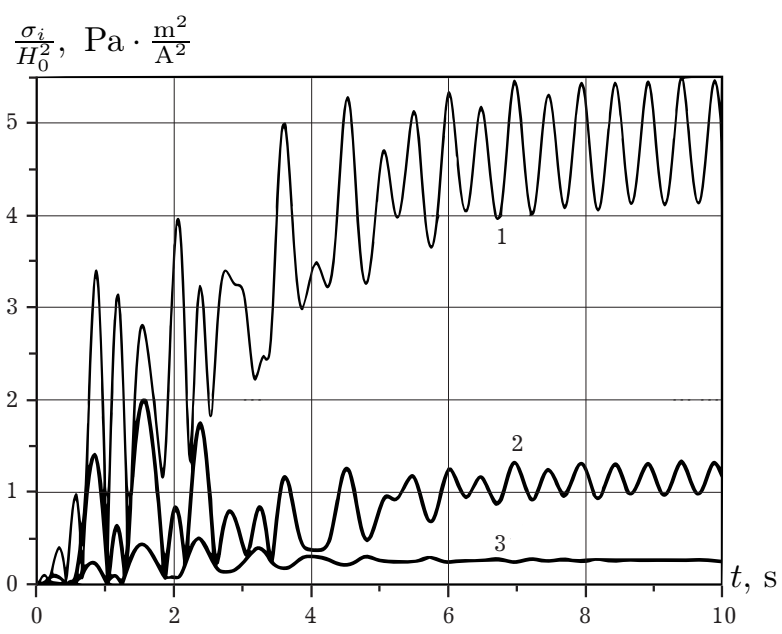

Fig. 4. Change in time of intensity of stresses $\sigma_{i}$ in the continuous cylinder.

Note that the temperature $T$ in Fig. 3 corresponds to the total temperature due to both the Joule heat $Q$ and the process of energy dissipation caused by ponderomotive force $F_{r}$ and taken into account according to the method described in $[8,11,12]$.

Stress intensities on all considered cylindrical surfaces have an oscillating nature of change in time, which is due to the nature of change in time of the total temperature and ponderomotive force. Stress intensities reach maximum values on the implant surface and decrease sharply when approaching the axis $r=0$. The maximum values of all considered physical quantities are reached on a surface $r=R$ of the cylinder. The maximum values of Joule heat $Q$ and ponderomotive force $F_{r}$ are reached in time $t \approx 0.1 t_{i}$, and temperature $T$ and stress intensity $\sigma_{i}$ are reached in time $t \approx 0.5 t_{i}$.

Based on the above given dependences of change in time $t$ and in radial coordinate $r$ for temperature $T$ (Fig. 3) and stress intensity $\sigma_{i}$ (Fig. 4) it is possible to conduct a qualitative and quantitative analysis of these physical quantities depending on the amplitude-frequency characteristics of the considered unstable EMF and the duration $t_{i}$ of its action.

Table 1.

\begin{tabular}{|c|c|c|c|}
\hline$t_{i}, \mathrm{~s}$ & $H_{0}, \mathrm{~A} / \mathrm{m}$ & $T, \mathrm{~K}$ & $\sigma_{i}, \mathrm{~Pa}$ \\
\hline \multirow{4}{*}{10} & 1 & $1.7 \cdot 10^{-7}$ & 5 \\
\cline { 2 - 4 } & 10 & $1.7 \cdot 10^{-5}$ & $5 \cdot 10^{2}$ \\
\cline { 2 - 4 } & $10^{2}$ & $1.7 \cdot 10^{-3}$ & $5 \cdot 10^{4}$ \\
\cline { 2 - 4 } & $10^{3}$ & 0.17 & $5 \cdot 10^{6}$ \\
\hline \multirow{4}{*}{100} & 1 & $1.7 \cdot 10^{-6}$ & 50 \\
\cline { 2 - 4 } & 10 & $1.7 \cdot 10^{-4}$ & $5 \cdot 10^{3}$ \\
\cline { 2 - 4 } & $10^{2}$ & $1.7 \cdot 10^{-2}$ & $5 \cdot 10^{5}$ \\
\cline { 2 - 4 } 300 & $10^{3}$ & 1.7 & $5 \cdot 10^{7}$ \\
\hline \multirow{4}{*}{600} & 1 & $5.1 \cdot 10^{-6}$ & 150 \\
\cline { 2 - 4 } & 10 & $5.1 \cdot 10^{-4}$ & $1.5 \cdot 10^{4}$ \\
\cline { 2 - 4 } & $10^{2}$ & $5.1 \cdot 10^{-2}$ & $1.5 \cdot 10^{6}$ \\
\cline { 2 - 4 } & $10^{3}$ & 5.1 & $1.5 \cdot 10^{8}$ \\
\cline { 2 - 4 } & 1 & $1.02 \cdot 10^{-5}$ & 300 \\
\cline { 2 - 4 } & 10 & $1.02 \cdot 10^{-3}$ & $3 \cdot 10^{4}$ \\
\cline { 2 - 4 } & $10^{2}$ & $1.02 \cdot 10^{-1}$ & $3 \cdot 10^{6}$ \\
\hline
\end{tabular}

The results of the numerical analysis are presented in Table 1.

Based on the data in Table 1, it is possible to predict the thermomechanical behavior of a cylindrical electrically conductive implant under the conditions of the patient staying with such an implant in external unstable EMFs having the character of impulsed EMFs with amplitude modulation.

\section{Conclusion}

A physico-mathematical model for determining the thermally stressed state of an electrically conductive cylindrical implant under the action of external unstable EMFs is proposed. Criteria for physiologically comfortable condition of a patient with an implant are formulated. These criteria take into account the known experimentally established limits of pain thermal and mechanical thresholds. On the basis of these criteria, it is possible to determine the maximum allowable values of amplitude-frequency 
characteristics and duration of action of external unstable EMFs for safe stay in them of the person with the considered implant.

A method for constructing solutions of initial-boundary value problems to find key functions - the axial component of the magnetic field vector, temperature, radial displacements and stress intensities in a cylindrical implant due to the action of external unstable EMFs - is proposed. This technique allows us to obtain expressions of key functions in the form convenient for computer analysis.

The maximum values of temperature, ponderomotive force and stress intensity in a cylindrical electrically conductive implant depending on the amplitude-frequency characteristics and duration of action of the unstable EMF are numerically analyzed. On the basis of the formulated criteria and the carried-out numerical researches, it is possible to analyze maximum admissible values of amplitudefrequency characteristics and duration of action of unstable EMF at observance of which the patient with the available implant will be provided with physiological comfort.

[1] Hoffmann O., Zafiropoulos G.-G. Tooth-implant connection: a review. Journal of Oral Implantology. 38 (2), 194-200 (2012).

[2] Gilbert Triplett R., Berger J., Jensen O., Louis P. Dental and Craniomaxillofacial Implant Surgery. Journal of Oral and Maxillofacial Surgery. 75 (8), e74-e93 (2017).

[3] Ozkan Y., Ozcan M., Varol A., Akoglu B., Ucankale M., Basa S. Resonance frequency analysis assessment of implant stability in labial onlay grafted posterior mandibles: a pilot clinical study. Int. Journal Oral Maxillofac Implants. 22 (2), 235-242 (2007).

[4] Taylor T. D., Agar J. R., Vogiatzi T. Implant prosthodontics: current perspective and future directions. Int. Journal Oral Maxillofac Implants. 15 (1), 66-75 (2000).

[5] Jaworski N., Iwaniec M. Numerical simulation of dental implant insertion process. 2017 XIIIth International Conference on Perspective Technologies and Methods in MEMS Design (MEMSTECH). 59-61 (2017).

[6] Batygin Yu. V., Lavinsky V. I., Himenko L. T. Impulse magnetic fields for advanced technologies. Harkov, MOST-Tornado Publ. (2003), (in Russian).

[7] Podstryhach Ja. S., Burak Ja. I., Hachkevich A. R., Cherniavskaia L. V. Thermoelasticity of electroconductive bodies. Kiev, Naukova dumka (1977), (in Russian).

[8] Hachkevych O. R., Musii R. S., Tarlakovskyi D. V. Thermomechanics of non-ferromagnetic electrically conductive bodies under the action of pulsed electromagnetic fields with amplitude modulation. Lviv, SPOLOM (2011), (in Ukrainian).

[9] Honorovskij I. S. Radiotechnical chains and signals. Moscow, Radio and communication (1986), (in Russian).

[10] Musii R., Melnyk N., Dmytruk V. Thermoelastic processes analyzer for piecewise homogeneous conductive structures subjected to pulsed electromagnetic action. Journal of Thermal Stresses. 41 (9), 1125-1135 (2018).

[11] Musij R. S. Dynamic problem of thermomechanics for conductive bodies of canonical form. Lviv, Rastr-7 (2010), (in Ukranian).

[12] Hachkevych O. R., Musii R. S., Stasiuk H. B. Problems of thermomechanics of electrically conductive bodies with plane-parallel limits under pulsed electromagnetic actions are connected. Lviv, Rastr-7 (2019), (in Ukranian).

[13] Hachkevych O., Musij R. Mathematical modeling in thermomechanics of electroconductive bodies under the action of the pulsed electromagnetic fields with modulation of amplitude. Mathematical Modeling and Computing. 6 (1), 30-36 (2019).

[14] Musii R., Mel'nyk N., Dmytruk V., Levus Y., Oryshchyn O., Nakonechny R. Computer prediction of operability of bimetal cylindrical sensors under the influence of radio-frequency pulses. 14th International Conference on Perspective Technologies and Methods in MEMS Design, MEMSTECH 2018 (Polyana, UKRAINE, 18-22 April 2018). 44-47 (2018). 
[15] Musij R., Dmytruk V., Melnyk N. Mathematical modeling and analysis of thermostressed state of bimetallic plate under electromagnetic action in the mode with pulse modulated signal. Mechanics and Mechanical Engineering. 22 (4), 865-870 (2018).

[16] Musii R., Melnyk N., Dmytruk V., Bilyk O., Kushka B., Shayner H. Modeling and calculation of the temperature-force regime of functioning of an electrical conductive spherical sensor under the action of an amplitude-modulated radio pulse. 15th International Conference on the Experience of Designing and Application of CAD Systems CADSM 2019 (Polyana-Svalyava, UKRAINE, February 26 - March 2, 2019). 5/45-48 (2019).

[17] Musij R., Drohomyretska K., Klapchuk M., Oryshchyn O., Nakonechnyy R. Solution of the connected problem of thermomechanics for a long hollow electroconductive cylinder under the action of impulse electromagnetic field with amplitude modulation. Mathematical Modeling and Computing. 5 (1), 48-55 (2018).

\title{
Термомеханічна поведінка електропровідного циліндричного імпланта за дії зовнішніх неусталених електромагнітних полів
}

\author{
Мусій Р. С., Мельник Н. Б., Дрогомирецька Х. Т., Закаулова Ю. В. \\ Національний університет "Львівсъка політехніка", \\ вул.С. Бандери, 12, 79013, Лъвів, Украӥна
}

\begin{abstract}
Запропоновано фізико-математичну модель визначення термонапружного стану електропровідного циліндричного імпланта за дії зовнішніх неусталених електромагнітних полів, зокрема імпульсних із модуляцією амплітуди. Дана модель дозволяє прогнозувати гранично допустимі, згідно з фізіологічними нормами, значення температури та інтенсивності напружень у розглядуваному імпланті залежно від параметрів зовнішніх неусталених електромагнітних полів та часу їх дії.
\end{abstract}

Ключові слова: електропровідний імплант, ииліндр, неусталене електромагнітне поле, температура, інтенсивності напружень, фізіологічні критерії. 